\title{
Gravity Effects in Microgap Flow Boiling
}

\author{
Franklin Robinson \\ Aerospace Engineer \\ Thermal Engineering Branch \\ NASA Goddard Space Flight Center \\ Greenbelt, MD 20771 \\ franklin.1.robinson@nasa.gov
}

\author{
Avram Bar-Cohen \\ Distinguished University Professor \\ Department of Mechanical Engineering \\ University of Maryland \\ College Park, MD 20742 \\ abc@umd.edu
}

\begin{abstract}
Increasing integration density of electronic components has exacerbated the thermal management challenges facing electronic system developers. The high power, heat flux, and volumetric heat generation of emerging devices are driving the transition from remote cooling, which relies on conduction and spreading, to embedded cooling, which facilitates direct contact between the heat-generating device and coolant flow. Microgap coolers employ the forced flow of dielectric fluids undergoing phase change in a heated channel between devices. While two-phase microcoolers are used routinely in ground-based systems, the lack of acceptable models and correlations for microgravity operation has limited their use for spacecraft thermal management. Previous research has revealed that gravitational acceleration plays a diminishing role as the channel diameter shrinks, but there is considerable variation among the proposed gravity-insensitive channel dimensions and minimal research on rectangular ducts. Reliable criteria for achieving gravity-insensitive flow boiling performance would enable spaceflight systems to exploit this powerful thermal management technique and reduce development time and costs through reliance on ground-based testing. In the present effort, the authors have studied the effect of evaporator orientation on flow boiling performance of HFE7100 in a $218 \mu \mathrm{m}$ tall by $13.0 \mathrm{~mm}$ wide microgap cooler. Similar heat transfer coefficients and critical heat flux were achieved across five evaporator orientations, indicating that the effect of gravity was negligible.
\end{abstract}

\section{Introduction and Motivation}

Increasing functionality and miniaturization of modern and emerging electronic components has exposed the limitations of the current remote cooling paradigm, which relies on conduction and spreading across multiple interfaces to dissipate waste heat. The large temperature gradient between the heat source and sink that results from remote cooling has led to electronic systems that are thermally limited, operating below the electrical capability of the device technology they exploit [1]. Embedded cooling overcomes these limitations by facilitating direct contact between the heat-generating device and coolant flow. Systems that enable the forced coolant flow to undergo phase change within the embedded channels provide additional benefits, such as higher heat transfer coefficients, smaller temperature gradients, hot spot mitigation, and lower pumping power requirements.

Space missions include an array of electronic and power systems, many of which could benefit from embedded cooling. These systems include power electronics, lidar and radar systems, power generation systems (e.g., Rankine cycle power plants, radioisotope thermoelectric generators, and fuel cells), and three-dimensional integrated circuits. The latest NASA Technology Roadmap [2] lists needs for (1) acquisition and removal of heat fluxes greater than $100 \mathrm{~W} / \mathrm{cm}^{2}$ over relatively small areas with tight temperature control $\left( \pm 1^{\circ} \mathrm{C}\right)$; (2) enhanced heat transfer surfaces with micro- and nanoscale features to enhance two-phase heat transfer at higher heat fluxes; and (3) high-capacity, two-phase heat transport systems for thermal control of large heat loads, such as those required by Rankine cycle power plants.

A key benefit of embedded two-phase cooling for space missions is the ability to deliver waste heat from the heat source to the radiator with little temperature drop. This enables the radiator to operate at higher temperatures, reducing the required heat rejection area and thereby reducing the radiator size and mass. For the same heat load in low earth orbit, a radiator operating at $20^{\circ} \mathrm{C}$ must be $34 \%$ larger than one operating at $40^{\circ} \mathrm{C}$. Other benefits of two-phase mechanically pumped fluid loops include longer transport distances with potential use of multiple evaporators and condensers and precise flow rate control, which increases heat flux limits and enables shutdown of the cooling system when necessary (e.g., when the heat generating device is unpowered or the spacecraft enters survival mode) [3].

One of the significant barriers to the widespread use of two-phase microcoolers is the complex nature of flow boiling, particularly for microgravity applications for which only limited experimental data is available. The complexity can be reduced through the use of a single, low aspect ratio channel (i.e., a microgap) rather than an array of parallel microchannels. This configuration mitigates flow instabilities and possible flow reversals as the vapor can expand both spanwise and downstream [4]. However, two-phase microgap coolers are not widely employed for spacecraft thermal management due to the lack of data and correlations for microgravity environments and the absence of acceptable models that could enable extrapolation of heat transfer and flow behavior from available terrestrial data.

Application of physics-based flow regime maps and an insightful reading of the two-phase literature reveals that gravitational acceleration plays a diminishing role as the channel diameter shrinks, thus facilitating more reliable extrapolation from existing databases. The goal of the present effort is to characterize the fluid physics governing two-phase flows in heated miniature and microscale rectangular ducts, with emphasis on methods for minimizing the effect of gravity in such flows. Experimental validation of gravityinsensitive behavior would enable spaceflight systems to exploit this powerful thermal management technique and reduce development time and costs through reliance on ground-based testing. 


\section{Microscale Definitions}

Microscale in the two-phase flow sense refers to flows for which the controlling mechanisms differ from those at the macroscale, with the influence of surface tension and shear forces increasing and that of gravity diminishing [5]. Accordingly, a literature review has been performed to find criteria for the transition to microscale two-phase flow behavior, beyond which gravity effects should be negligible. Many microchannel definitions have been proposed, including those based on channel geometry alone and those relating to a combination of channel size and fluid properties such as surface tension and the density difference between the liquid and vapor. Recent definitions have incorporated additional terms, such as viscosity, mass flux, and contact angle.

\section{Definitions based on Geometry Alone}

Mehendale, Jacobi, and Shah [6] classified hydraulic diameters greater than $6 \mathrm{~mm}$ as macroscale, those from 1 to 6 $\mathrm{mm}$ as compact, those from 0.1 to $1 \mathrm{~mm}$ as mesoscale, and those from 0.001 to $0.1 \mathrm{~mm}$ as microscale. Kandlikar [7], based on manufacturing techniques, defined conventional channels as those with hydraulic diameters less than $3 \mathrm{~mm}$, minichannels as those with hydraulic diameters less than 3 $\mathrm{mm}$ and greater than $200 \mu \mathrm{m}$, and microchannels as those with hydraulic diameters less than $200 \mu \mathrm{m}$. Such definitions based on geometry alone capture the compact nature of the channels, but fail to characterize the underlying change in the two-phase fluid behavior.

\section{Definitions based on the Eötvös Number}

Many microchannel definitions are some variation of the ratio between the gravitational forces $\left(\Delta \rho \cdot g \cdot D_{h}\right)$ and surface tension forces $\left(\sigma / D_{h}\right)$ within the system. A useful way to assemble and compare these criteria is to reduce each one to its equivalent Eötvös number, $E o$, defined as

$$
E o=\frac{\Delta \rho \cdot g \cdot D_{h}{ }^{2}}{\sigma}
$$

where $\Delta \rho$ is the density difference between the liquid and vapor phases of the working fluid, $g$ is the acceleration due to gravity, $D_{h}$ is the hydraulic diameter $\left(D_{h}=4 \cdot A_{c} / P\right.$ where $A_{c}$ is the cross sectional area and $P$ is the wetted perimeter), and $\sigma$ is the surface tension of the working fluid. Low values of the Eötvös number indicate that surface tension dominates.

In 1963, Suo and Griffith [8] studied mixtures of liquid water, n-heptane, and n-octane with gaseous air, nitrogen, and helium in tubes with radii from 0.514 to $0.795 \mathrm{~mm}$. They observed that liquid slugs in adiabatic horizontal tubes exhibited an insensitivity to gravity when

$$
\begin{gathered}
\Omega=\frac{\rho_{l} \cdot g \cdot r^{2}}{\sigma}<0.22 \\
\rho_{l} / \rho_{g} \gg 1 \\
\mu_{l} / \mu_{g}>25
\end{gathered}
$$

where $\Omega$ represents the ratio of gravitational forces to surface tension forces, $\rho_{l}$ and $\rho_{g}$ are the liquid and vapor densities, respectively, $r$ is the tube radius, and $\mu_{l}$ and $\mu_{g}$ are the liquid and vapor dynamic viscosities, respectively. By replacing the liquid density with the density difference between the liquid and vapor phases, which introduces only a small error due to the constraint of $\rho_{l} / \rho_{g} \gg 1$, and using the tube diameter rather than the radius, the Suo and Griffith criterion for the microscale transition can be rewritten as $E o<0.88$.

In 1992, Brauner and Moalem Maron [9], using the stratified/nonstratified transitional boundary as their guide, identified microchannels as those with Eo $<4 \pi^{2}$. Brauner [10] had previously provided the same definition to define channels subjected to Earth's gravity that exhibited similar behavior to that expected in microgravity.

In 1997, Kew and Cornwell [11] found that established correlations predicted heat transfer coefficients reasonably well for flow boiling of R141b in tubes with diameters of 3.69 and $2.87 \mathrm{~mm}$, but performed poorly when applied to a tube with a diameter of $1.39 \mathrm{~mm}$. They suggested that microscale behavior was exhibited when $C o \geq 0.5$. Cornwell and Kew [12] had previously introduced the confinement number, Co.

$$
C o=\frac{1}{D} \sqrt{\frac{\sigma}{\Delta \rho \cdot g}}
$$

The Eötvös and confinement numbers are therefore related through the following expression.

$$
E o=\frac{1}{C o^{2}}
$$

Thus, the Kew and Cornwell criterion for microchannels can be rewritten as $E o \leq 4$.

In 1999, Triplett et al. $[13,14]$ studied flow patterns, void fraction, and pressure drop of air-water mixtures in circular channels with diameters of 1.10 and $1.45 \mathrm{~mm}$ and semitriangular channels with hydraulic diameters of 1.09 and 1.49 $\mathrm{mm}$. They suggested microchannels are those with hydraulic diameters smaller than the Laplace constant, La.

$$
L a=\sqrt{\frac{\sigma}{\Delta \rho \cdot g}}
$$

The Triplett et al. criterion can be rewritten as $E o<1$.

In 2003, Li and Wang [15] studied the effect of tube size on condensation in mini- and micro-tubes using an analytical model. They found that flow patterns in small channels were limited to annular, lengthened bubble, and bubbly flow. They argued that the effect of gravity on the flow regime could be ignored and the thickness of the annular liquid film around the tube would deviate by no more than $1 \%$ when

$$
D \leq 0.224 \cdot \sqrt{\frac{\sigma}{\Delta \rho \cdot g}}
$$


which can be rewritten as $E o \leq 0.5$. Follow on work in 2006 by Cheng and $\mathrm{Wu}$ [16] indicated that gravity-insensitive behavior was seen in systems with $E o<0.05$. The authors also found that surface tension becomes dominant and the gravitational effect is small in systems with $0.05<E o<3$.

In 2007, Ullman and Brauner [17] classified channel sizes based on flow patterns and their transitions. They found that modified flow pattern transitions were required for systems with $E o<1.6$. The authors also noted that - in calculating the Eötvös number for noncircular tubes - the hydraulic diameter might not represent correctly the significance of gravity and surface tensions forces (a concern also voiced by Baldassari and Marengo [18]). For rectangular ducts configured with their width and axial length normal to the gravity vector, Ullman and Brauner proposed that

$$
E o=\frac{\Delta \rho \cdot g \cdot H \cdot W}{\sigma}
$$

where $H$ is the channel height and $W$ is the channel width. This variation of the Eötvös number accounts for the gravity term scaling with the channel height $(\Delta \rho \cdot g \cdot H)$ and the surface tension term scaling with the channel width $(\sigma / W)$. The effect of this modification for HFE7100 in a $13.0 \mathrm{~mm}$ wide channel for channel heights from 1 to $10,000 \mu \mathrm{m}$ is shown in Figure 1. HFE7100 fluid properties were obtained from Rausch et al. [19]. The horizontal black lines represent the maximum $\left(4 \pi^{2}\right)$ and minimum $(0.05)$ values of the microscale Eötvös numbers proposed by various authors. The area of interest (i.e., the shape confined by the red, blue, and black lines) covers a range of channel heights spanning four orders of magnitude, revealing the significance of using the appropriate formulation of the Eötvös number. To the authors' knowledge, no experimental studies have been performed to assess which formulation is appropriate for rectangular ducts.

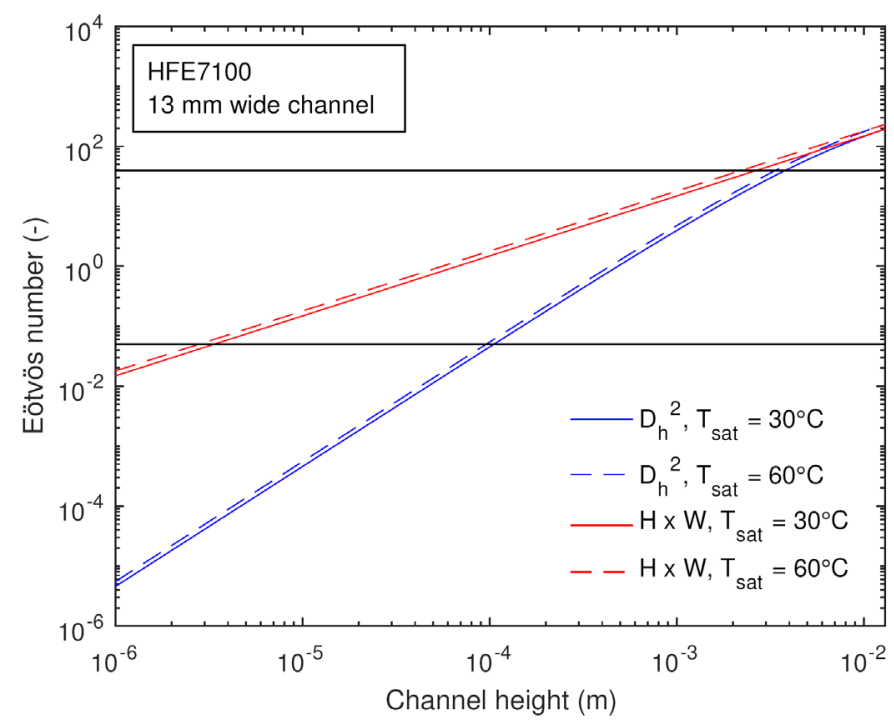

Figure 1: Large variation in the Eötvös number results from differing formulations based on hydraulic diameter (Equation 1) and channel height and width (Equation 9)

In 2011, Ong and Thome [20] studied flow boiling pattern transitions and compared the liquid film thickness between the top and bottom of the channel for tubes with diameters of $1.03,2.20$, and $3.04 \mathrm{~mm}$ and working fluids R134a, R236fa, and R245fa. They observed a gradual transition from macroscale to microscale. The authors proposed $\mathrm{Co}>0.3-0.4$ as the boundary for macroscale behavior and $C o>1.0$ as the upper boundary for symmetric microscale flow. These values correspond to Eo $<6.25$ for the boundary for macroscale (using $C o=0.4$ ) and $E o<1$ for the boundary for symmetric microscale flow.

Figure 2 shows the threshold Eötvös numbers for microscale two-phase flow proposed by the various authors discussed in this section. The ratio between the maximum and minimum values is nearly 800 . Some of the variation can be attributed to the variation among the parameters each author used to assess microscale behavior. Authors who studied the absence of stratified flow generally reported higher values and authors who studied the uniformity of the liquid film thickness in annular flow reported lower values. Nonetheless, there exists significant variation among the criteria even when authors report using the same phenomenon to determine their microscale criterion. The wide variation suggests that the Eötvös number alone may not capture adequately the transition to microscale two-phase flow.

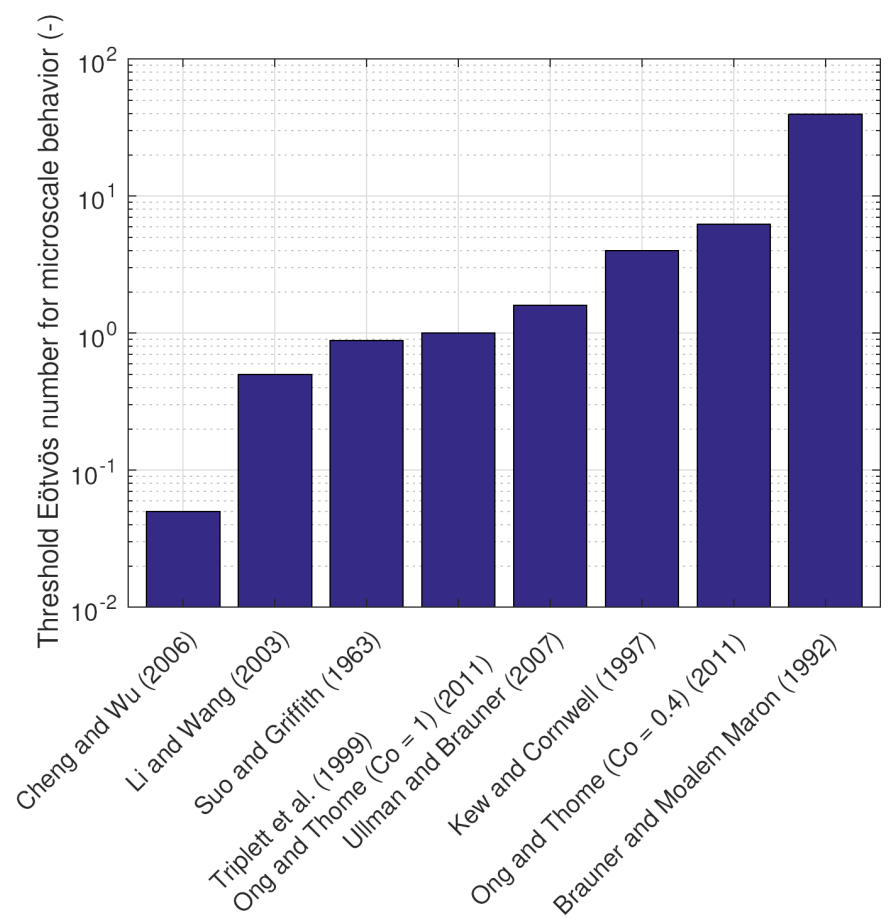

Figure 2: Eötvös numbers for microscale behavior proposed by various authors span three orders of magnitude

\section{Definitions beyond the Eötvös Number}

Recent efforts have considered additional terms to assess the transition to microscale two-phase flow behavior. In 2010, Harirchian and Garimella [21] studied confinement effects in flow boiling of FC77 in $12.7 \mathrm{~mm}$ long channels with widths of 100 to $5850 \mu \mathrm{m}$ and depths of 100 to $400 \mu \mathrm{m}$. The authors suggested that - in addition to channel size and fluid properties - mass flux also governs bubble confinement. They observed confined flows when the convective confinement number, $B o^{0.5} \cdot R e$, was less than 160 with 


$$
\begin{gathered}
B o=\frac{\Delta \rho \cdot g \cdot D^{2}}{\sigma} \\
R e=\frac{G \cdot D}{\mu_{l}}
\end{gathered}
$$

where $B o$ is the Bond number, $D=\sqrt{A_{c}}$, and $G$ is the mass flux. Earlier work by Harirchian and Garimella [22] revealed that the channel cross-sectional area played a critical role in determining microchannel heat transfer mechanisms and thus, the characteristic length used in their analysis is the square root of the channel cross section rather than the hydraulic diameter. The modification in calculating the Bond number produces the same value that Ullman and Brauner [17] proposed for rectangular ducts, assuming the channel is oriented horizontally (the Bond and Eötvös numbers have identical formulations in the context of the present study). The effect of the modification for HFE7100 at $101.3 \mathrm{kPa}$ in a 13.0 $\mathrm{mm}$ wide channel for channel heights from 1 to $10,000 \mu \mathrm{m}$ is shown in Figure 3.

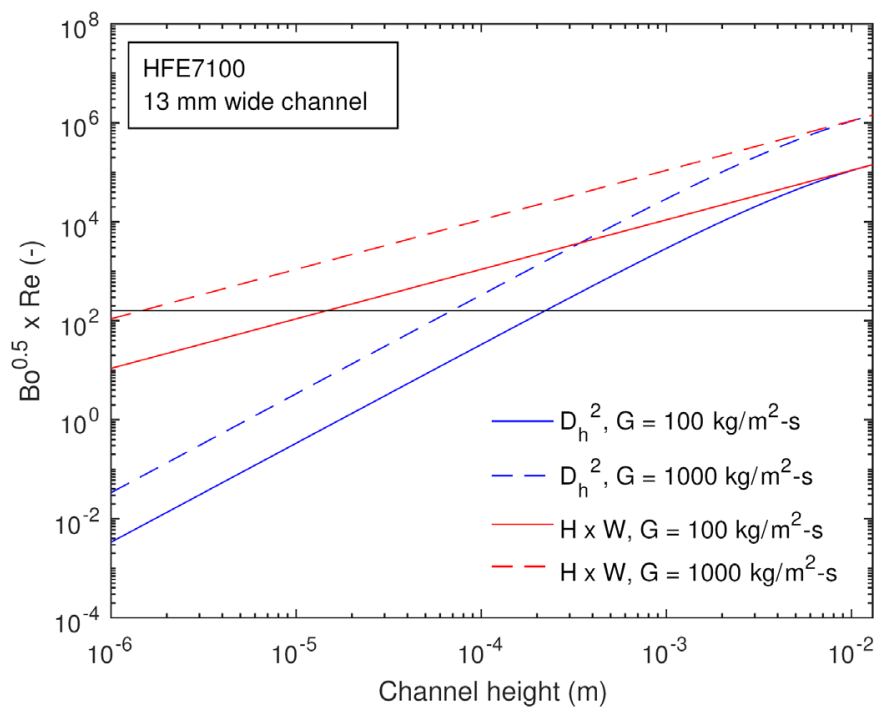

Figure 3: Large variation in the convective confinement number results from formulations based on hydraulic diameter (Equation 1) and channel cross section (Equation 10)

In 2015, Tibirica and Ribatski [23], by combining a broad literature review with their own experiments using tubes with diameters from 1.00 to $2.32 \mathrm{~mm}$, concluded that the key characteristics of microscale tubes are (1) the absence of stratified flows and (2) uniformity of the liquid film thickness along the tube perimeter for slug and annular flows in horizontal channels. Using an analytical model, they determined the maximum diameter for which a liquid slug could exist in a tube under static conditions was

$$
D_{h}=\sqrt{\frac{8 \cdot \sigma \cdot \cos \theta}{\left(\rho_{l}-\rho_{v}\right) \cdot g}}=L a \cdot \sqrt{8 \cdot \cos \theta}
$$

where $\theta$ is the contact angle and $\rho_{v}$ is the vapor density. Thus, stratified flow is not expected when $E o<8 \cdot \cos \theta$. Based on their experiments and the model of Kandlikar [5], the authors indicated that uniform film thickness was obtained when the gravitational force is less than $5 \%$ of the surface tension force.

$$
\frac{F_{\text {gravity }}}{F_{\sigma}}=\frac{\Delta \rho \cdot g \cdot D^{2}}{\sigma}=E o<0.05
$$

Thus, the uniform film thickness criterion proposed by Tibirica and Ribatski [23] matches the microchannel criterion of Cheng and $\mathrm{Wu}[16]$.

\section{Summary of Microchannel Definitions}

The recent criteria for the transition to microscale behavior cannot be reduced to the Eötvös number alone. Therefore, to provide a comparison among all of the proposed microscale criteria, Figure 4 shows the range of diameters at which various authors have suggested the transition to microscale behavior begins for saturated water, R245fa, and HFE7100 at $101.3 \mathrm{kPa}$ (corresponding to saturation temperatures of 100.0 , 15.1 , and $59.8^{\circ} \mathrm{C}$, respectively). The fluid properties for water and R245fa were obtained from REFPROP Version 9.1 [24] (which calculates properties for water according to Wagner and Pruss [25] and R245fa according to Lemmon and Span [26]) and those for HFE7100 were obtained from Rausch et al. [19]. The contact angles for water and R245fa are from [23] and for HFE7100 from [27]. It is assumed that the channels have circular cross sections, thereby providing identical values for the physical and hydraulic diameters.

The most conservative estimates for the transition to microscale two-phase flow behavior in circular channels are 0.336, 0.237, and $0.191 \mathrm{~mm}$ for water, R245fa, and HFE7100, respectively, and the most relaxed values are 15.7, 6.65, and $5.36 \mathrm{~mm}$, respectively. The large variation among the proposed criteria (spanning two orders of magnitude for circular ducts) suggests additional research is required to clarify the microscale transition and that there may be additional parameters that influence gravity-insensitivity.

Some studies have been performed with the aim of better understanding the role of gravity on two-phase flow behavior (rather than parameters that provide gravity-insensitivity), but those efforts cannot be covered comprehensively in this paper due to length constraints. The authors refer readers searching for additional details to several review papers [18, 28-30].

\section{Objectives}

The literature review revealed a wide range of criteria for predicting the transition to microchannel two-phase flow behavior. The large variation in the criteria, coupled with the unresolved issue of which length scales are appropriate for calculating the Eötvös for rectangular ducts, prevents the reliable use of existing criteria without further validation. Accordingly, a research program was initiated to:

1. Characterize the parameters, including channel size, fluid velocity, fluid properties, flow regime, vapor quality, and heat flux, that provide gravity-insensitive flow boiling performance in microgap coolers;

2. Determine the appropriate metric for assessing gravityinsensitive flow boiling performance (e.g., flow regimes and their transitions; measurements such as heat transfer coefficients and pressure drop; or instabilities, such as critical heat flux and local dryout); and 
3. Assess the role of microgap channel length, in which the flow is never "fully developed," on two-phase flow characteristics and the onset of gravity-insensitive behavior.
As a first step in meeting these objectives, a test facility has been developed and preliminary experiments on the flow boiling performance of HFE7100 in a $218 \mu \mathrm{m}$ tall by $13.0 \mathrm{~mm}$ wide microgap have been performed.

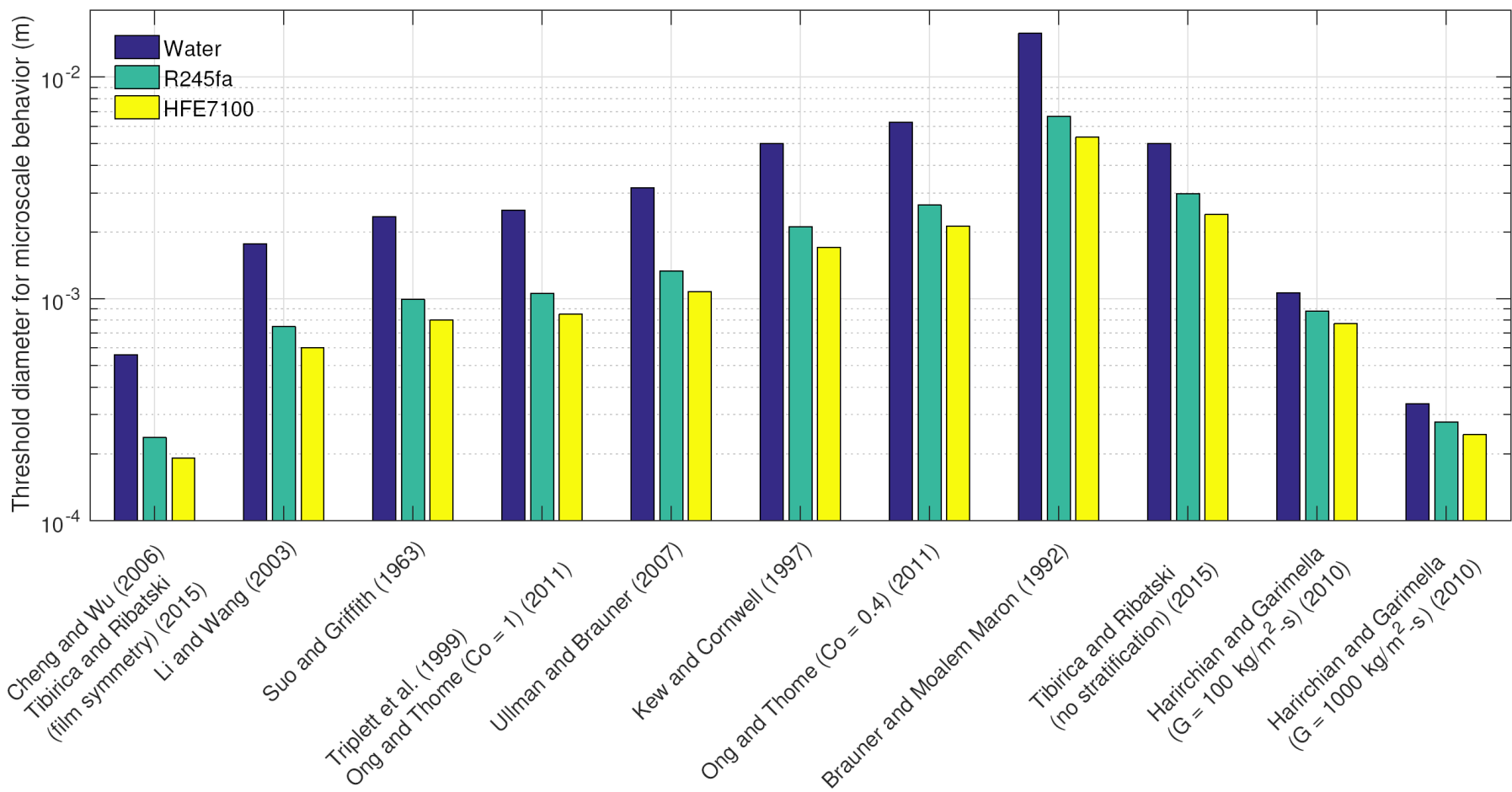

Figure 4: Microscale diameters for circular channels for saturated water, R245fa, and HFE7100 at $101.3 \mathrm{kPa}$

\section{Experiment}

\section{Hardware}

An experimental apparatus was designed and assembled to provide two-phase flow test data with the evaporator in various orientations with respect to the gravity vector. The flow loop for orientation testing, a schematic of which is shown in Figure 5, supplies degassed fluid to the evaporator test section at the prescribed flow rate, temperature, and pressure. The working fluid is circulated by a gear pump with an electromagnetic drive (Micropump Series GA with EagleDrive). The preheater provides the desired liquid subcooling at the inlet to the evaporator test section. Fluid leaving the evaporator is condensed and/or subcooled via a plate heat exchanger (Lytron LL520G14) connected to a recirculating chiller (Julabo FP50). The circulator working fluid is distilled water. A $15 \mu \mathrm{m}$ sintered metal filter collects particulate contamination within the flow loop. The tubing material throughout the loop is stainless steel. A temperaturecontrolled, two-phase reservoir regulates the low-side pressure for the loop and compensates for the expansion and contraction of the working fluid during testing.

The liquid flow rate is measured by a Pelton-type microturbine liquid flow sensor with a range of 20-200 $\mathrm{ml} / \mathrm{min}$ and accuracy of $\pm 0.5 \%$ of the full scale rating (McMillan Flow Products Model 104). The fluid temperature is measured via four-wire, class $1 / 10 \mathrm{DIN}, 100 \Omega$ resistance temperature detector probes at the preheater inlet, preheater outlet, condenser inlet, condenser outlet, and reservoir vapor space. The fluid temperature is measured via $0.51 \mathrm{~mm}$ diameter stainless steel type-T grounded thermocouple probes at the evaporator inlet and outlet. The absolute pressure is measured in the reservoir vapor space and evaporator inlet by silicon, strain gauge type transducers with ranges of 0 to 300 $\mathrm{kPa}$ and accuracies of $\pm 0.1 \%$ of the full scale rating (Honeywell FP2000). The differential pressure between the evaporator inlet and outlet manifolds is measured by a variable reluctance pressure sensor with replaceable pressure sensing diaphragms, each with an accuracy of $\pm 0.25 \%$ of the full scale rating (Validyne Engineering DP15).

The working fluid is HFE7100, due to its saturation properties (boiling point of $59.8^{\circ} \mathrm{C}$ at $101.3 \mathrm{kPa}$ ), low freezing point $\left(-135^{\circ} \mathrm{C}\right)$, low electrical conductivity, non-toxicity, and non-flammability. The flow loop was designed to minimize the system leak rate due to concerns of air infiltrating the system, which could affect the fluid properties and boiling performance of the degassed fluid. Chen and Garimella [31] found that undegassed FC77, relative to degassed FC77, experienced higher pressure drops and more flow instability; "pseudo-boiling" (i.e., the formation of air-vapor bubbles that alter the flow field but do not enhance boiling heat transfer); and lower boiling incipience temperatures. Similar results were found by Muller-Steinhagen, Epstein, and Watkinson [32] and Sawada et al. [33]. Another compelling reason to ensure the degassed fluid remains free of air is that published properties are available exclusively for the degassed fluid. Weld, VCR, and ConFlat fittings and flanges were used wherever possible due to their very low leak rates. Prior to 
charging the loop, the working fluid was subjected to multiple freeze-pump-thaw cycles to remove non-condensable gases. The saturation pressure and temperature of the degassed fluid were measured and compared against reference data [34] to verify that the non-condensable gases had been removed.

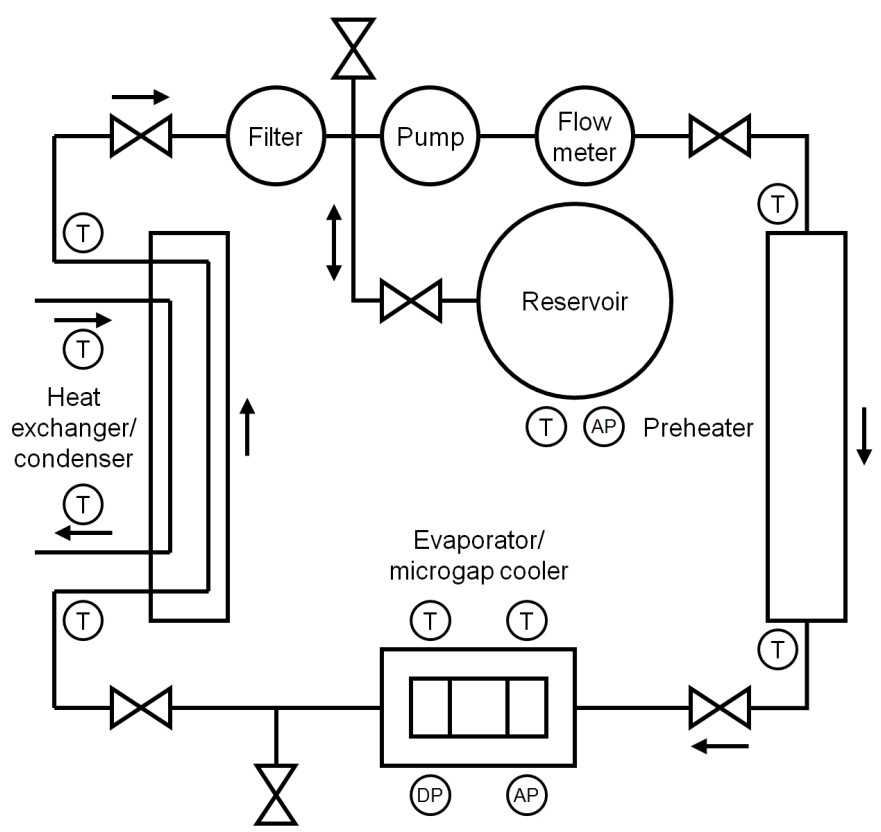

Figure 5: Flow loop schematic

The heat source for the evaporator is a $12.7 \mathrm{~mm}$ by 12.7 $\mathrm{mm}$ by $0.6 \mathrm{~mm}$ silicon thermal test chip (TTC) mounted to a printed circuit board (Thermal Engineering Associates TTV4102). The TTC provides uniform heating with a four-wire heater circuit design to eliminate parasitic heat losses in the supply wiring. The resistors cover more than $85 \%$ of the die area. Ten temperature-sensing diodes provide temperature measurements of the TTC. The diodes are located on the chip frontside. Measurements of the surface via confocal microscopy revealed an average roughness of $0.031 \mu \mathrm{m} \pm 0.018 \mu \mathrm{m}$.

The diodes on the TTC are calibrated using a constant temperature air oven and a four-wire, class $1 / 10 \mathrm{DIN}, 100 \Omega$ resistance temperature detector probe. The temperature of the oven was held constant until consecutive readings of temperature and resistance, taken 10 minutes apart, varied by less than $0.1^{\circ} \mathrm{C}$ and $1 \Omega$, respectively.

The evaporator assembly, shown in Figure 6 and Figure 7 , is composed of a thermal isolator base (not shown), base plate, thermal test vehicle, fluid enclosure, polycarbonate cover, top plate, and thermal isolator cap (not shown). The fluid enclosure includes the fluid inlet and outlet taps and manifolds, pressure taps for absolute and differential pressure measurements, and the evaporator inlet and outlet fluid temperature probes. Replaceable, transparent polycarbonate covers are inset to the fluid enclosure. The microgap is located between the exposed face of the TTC and the interior face of the polycarbonate cover. Isolators minimize thermal losses to the ambient air and mounting plate.

A Keyence VHX-5000 digital microscope with a 100 to $1000 \mathrm{x}$ objective and precision stage was used to measure the microgap height. The height of the stage was adjusted in 10 $\mu \mathrm{m}$ increments until the top of the silicon TTC was in focus. Using this height as the zero reference, the height of the stage was then adjusted until the bottom of the polycarbonate cover was in focus to determine the microgap height. The uncertainty of this measurement technique is approximately one full increment in the vertical direction due to the reliance on the operator to declare the image in focus $( \pm 10 \mu \mathrm{m})$. For the present assembly, nine measurements were taken, which produced an average microgap height of $229 \mu \mathrm{m}$, standard deviation of $7 \mu \mathrm{m}$, and range of 220 to $240 \mu \mathrm{m}$.

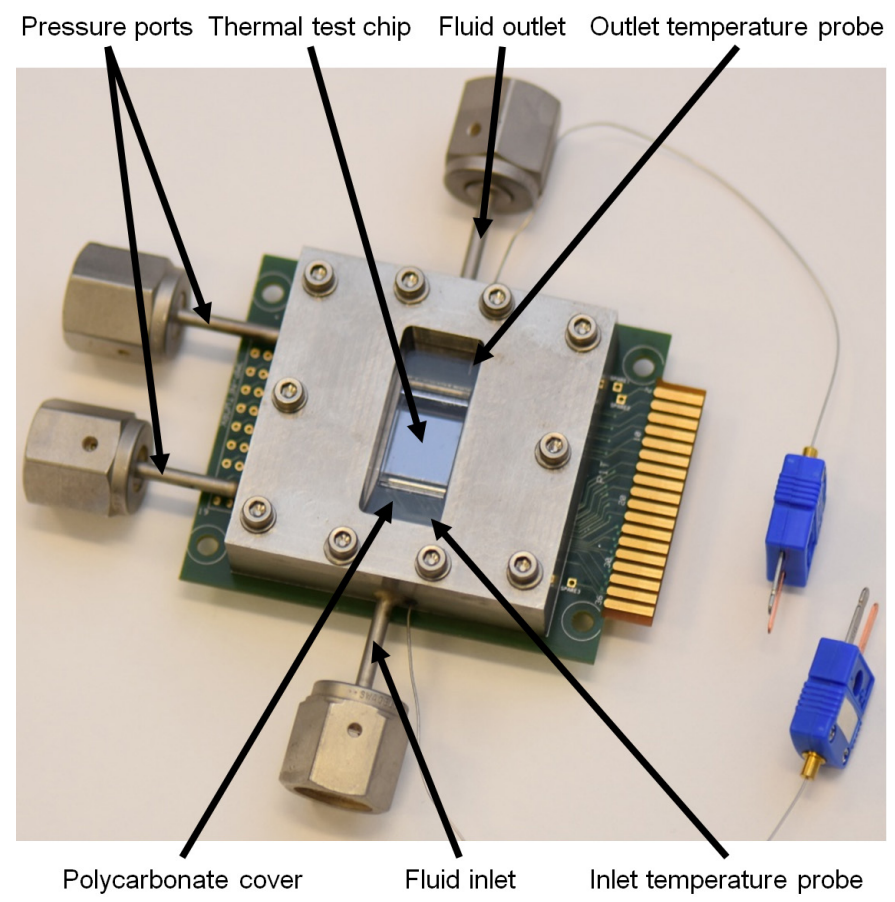

Figure 6: Evaporator assembly

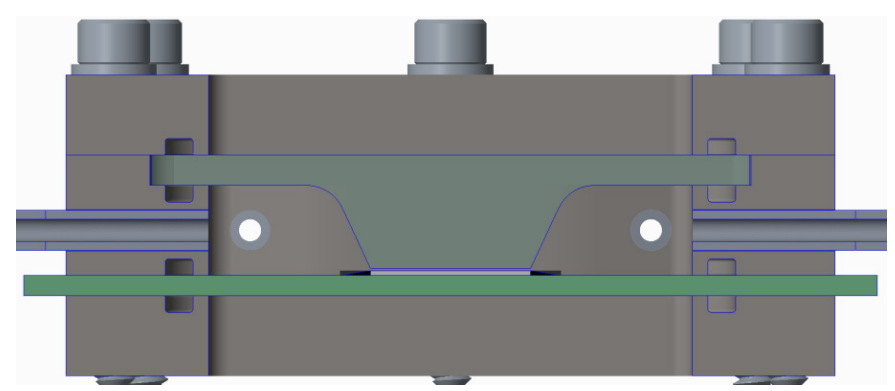

Figure 7: Axial cross section of evaporator assembly (to scale)

The optical measurements of the microgap height were performed at $22{ }^{\circ} \mathrm{C}$ with the interior cavity of the flow enclosure open to atmospheric pressure. During two-phase testing, the flow enclosure and polycarbonate temperature was 55 to $60{ }^{\circ} \mathrm{C}$ based on a nominal inlet saturation temperature of $61{ }^{\circ} \mathrm{C}$, liquid inlet subcooling of 2 to $6{ }^{\circ} \mathrm{C}$, and convective losses to the ambient air. The pressure effect on the microgap height was neglected, as the saturation pressure of HFE7100 at $60{ }^{\circ} \mathrm{C}$ is very close to atmospheric pressure. Accounting for the thermal expansion of the polycarbonate cover island and stainless steel enclosure up to the ledge on which the polycarbonate cover rests and assuming a temperature rise of $35^{\circ} \mathrm{C}$ 
results in an estimated reduction in the microgap height of 11 $\mu \mathrm{m}$. Thus, the predicted microgap height is $218 \mu \mathrm{m}$.

\section{Orientations}

In order to produce a range of gravity effects while in terrestrial gravity, the evaporator was configured in five orientations: horizontal heater up (HU), vertical upflow (VU), horizontal heater down (HD), vertical downflow (VD), and sideways (SW), as shown graphically in Figure 8.

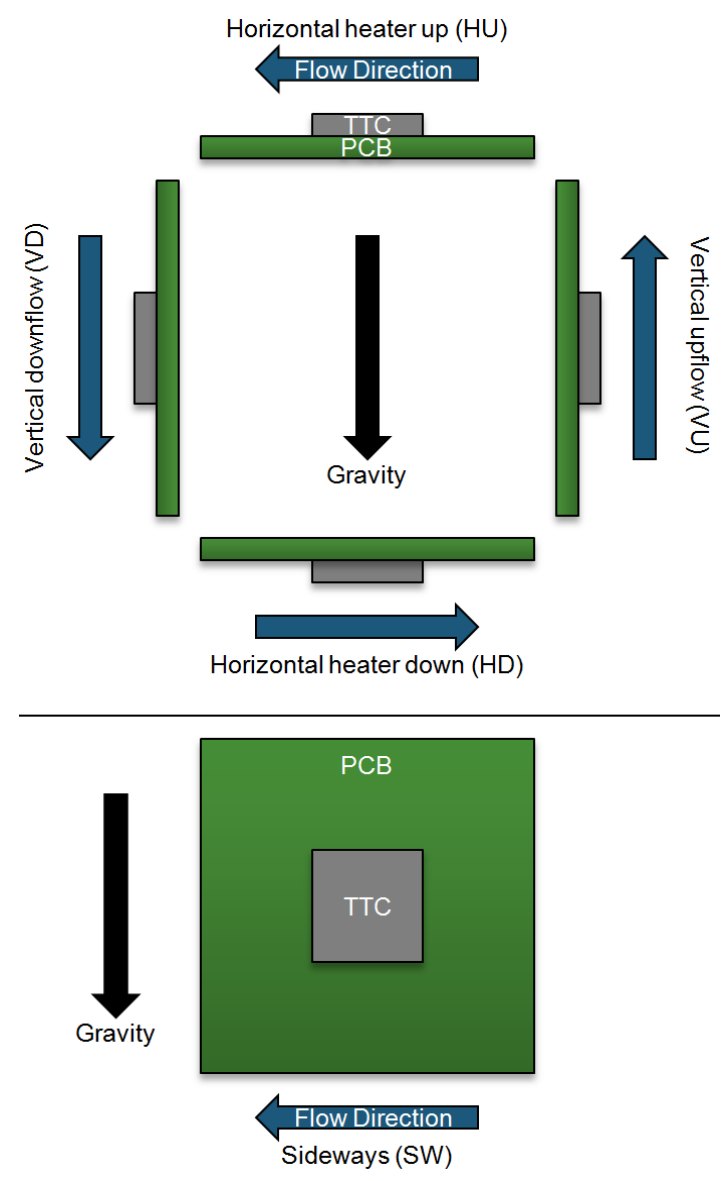

Figure 8: Evaporator orientations

The appropriate length scales used in the calculation of the Eötvös number remain a subject of debate, as discussed in the "Microscale Definitions" section. Table 1 lists the Eötvös number for each orientation using three length scales:

1. Conventional definition of the hydraulic diameter, squared;

2. Cross sectional area of the microgap channel, $H \cdot W$; and

3. Channel width, $W$, for the surface tension term and length in the direction of the gravity vector (i.e., $H$ for the HU and HD configurations, $L$ for the VU and VD configurations, and $W$ for the SW configuration) for the gravity term.

The calculations revealed that:

1. Eo is constant across all five orientations when calculation methods 1 and 2 are employed;

2. Calculation method 3 shows a strong dependence on orientation, producing results that vary by a factor of 60 ; and
3. Calculation methods 2 and 3 produce identical results for the horizontal configurations, which results from the microgap height being in the direction of the gravity vector in those configurations.

4. Based on the various proposed Eötvös number criteria for the transition to microscale, the microgap may or may not behave as a microchannel and therefore, may or may not provide gravity-insensitive flow boiling performance.

Table 1: Eötvös number varies by factor of 900 for fixed geometry depending on calculation method

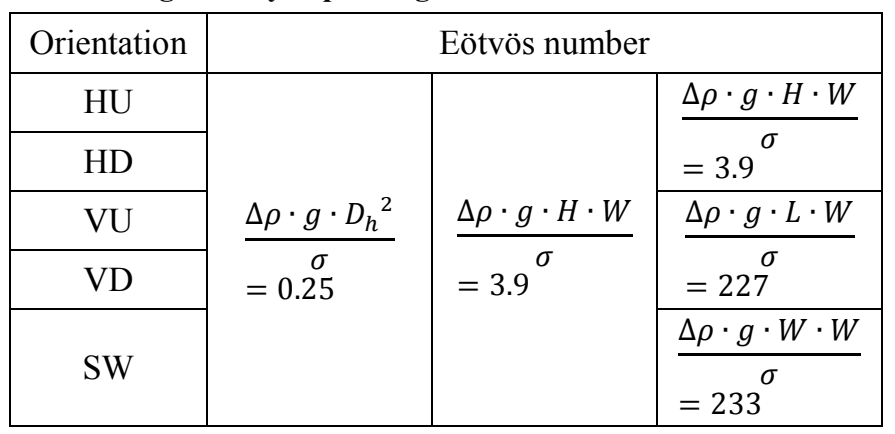

\section{Characterization of Heat Losses to Ambient}

Prior to performing two-phase flow studies, the test facility was characterized to assess the thermal losses to ambient. Two thermal resistance paths control the temperature of the TTC. Both paths begin at the resistors located on the frontside of the TTC. The upward path is a series of conduction through the silicon TTC and convection into the fluid flow, with thermal resistances defined as

$$
\begin{gathered}
R_{\text {up }}=R_{\text {cond }, S i}+R_{\text {conv }} \\
R_{\text {cond }, S i}=\frac{t_{S i}}{k_{S i} \cdot A_{\text {chip }}} \\
R_{\text {conv }}=\frac{1}{H T C \cdot A_{\text {chip }}}
\end{gathered}
$$

where $R_{u p}$ is the thermal resistance of the upward path, $R_{\text {cond,Si }}$ is the thermal resistance due to conduction through the silicon, $t_{S i}$ is the thickness of the silicon, $k_{S i}$ is the thermal conductivity of the silicon, $A_{\text {chip }}$ is the area of the TTC exposed to the fluid flow, $R_{\text {conv }}$ is the thermal resistance due to convection to the fluid, and HTC is the heat transfer coefficient. The downward path is a series of conduction through the solder and underfill, conduction through the printed circuit board, and conduction through the stainless steel flow enclosure. The complexity of the downward path makes the thermal resistance difficult to estimate analytically. In order to estimate the resistance of the downward path, the flow enclosure was evacuated to vacuum, heat was added to the TTC, and the temperature difference between the TTC and flow enclosure was recorded after steady state was achieved. The temperature difference was measured as the TTC power was increased to $5 \mathrm{~W}$ in $1 \mathrm{~W}$ increments and while the power was subsequently decreased in $1 \mathrm{~W}$ increments. 
A linear regression was applied to each set of temperature versus power data. The slope of each regression represents the thermal resistance between the diode and stainless steel enclosure. Table 2 provides the thermal resistance of the downward path for each diode. Diode 6, located at the center of the TTC, has the highest thermal resistance and diode 10, located immediately adjacent to the stainless steel housing, has the lowest thermal resistance. Diode 2 is representative of the diodes that fall between the maximum and minimum.

Table 2: Downward thermal resistance for each diode

\begin{tabular}{|c|c|c|}
\hline Diode & $\begin{array}{c}\text { Thermal } \\
\text { Resistance } \\
\text { (K/W) }\end{array}$ & $\begin{array}{c}\text { Correlation } \\
\text { Coefficient } \\
\text { Squared }\end{array}$ \\
\hline 1 & 13.42 & 0.9998 \\
\hline 2 & 13.89 & 0.9998 \\
\hline 3 & 14.05 & 0.9998 \\
\hline 4 & 13.62 & 0.9998 \\
\hline 5 & 14.27 & 0.9997 \\
\hline 6 & 14.68 & 0.9997 \\
\hline 7 & 14.53 & 0.9998 \\
\hline 8 & 13.81 & 0.9998 \\
\hline 9 & 13.57 & 0.9998 \\
\hline 10 & 13.06 & 0.9998 \\
\hline
\end{tabular}

Figure 9 shows the fraction of the TTC heater power that enters the fluid and the fraction of the convective resistance to the total upward resistance as a function of heat transfer coefficient. The calculations assume a uniform heat transfer coefficient across the TTC and a constant silicon thermal conductivity of $113.7 \mathrm{~W} / \mathrm{m}-\mathrm{K}$ at $90{ }^{\circ} \mathrm{C}$. The variation in downward thermal resistance among the diodes has a minimal effect on the fraction of the heat entering the fluid. For diode 2 , which represents an average diode on the TTC, $80 \%$ of the heat enters the fluid for heat transfer coefficients above 1,800 $\mathrm{W} / \mathrm{m}^{2}-\mathrm{K}, 90 \%$ of the heat enters the fluid for heat transfer coefficients above $4,100 \mathrm{~W} / \mathrm{m}^{2}-\mathrm{K}$, and $95 \%$ of the heat enters the fluid for heat transfer coefficients above $8,900 \mathrm{~W} / \mathrm{m}^{2}-\mathrm{K}$.

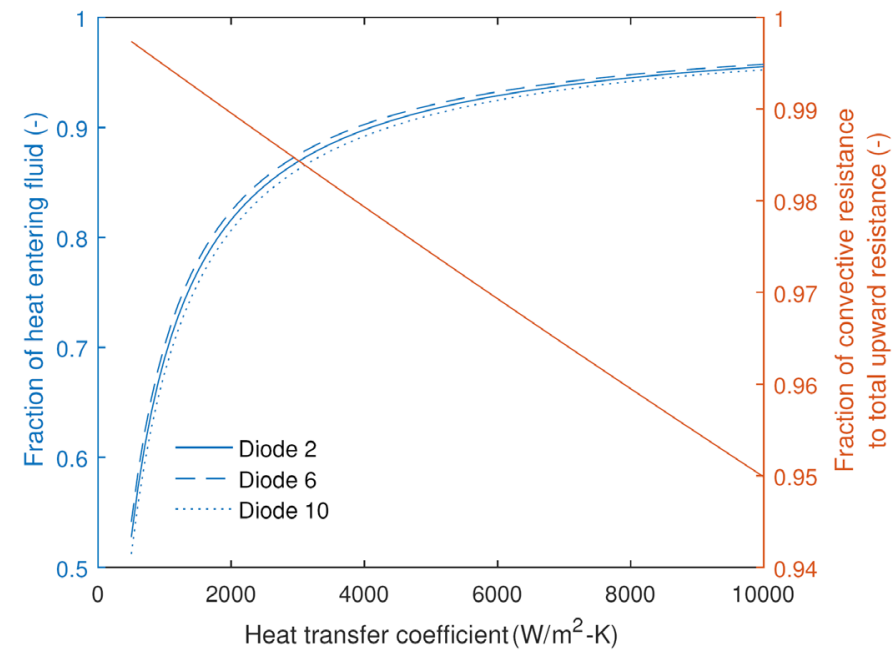

Figure 9: More than $80 \%$ of the heat enters the fluid for most of the operational space

Based on the characterization study, the heat lost to ambient $\left(q_{\text {loss }}\right)$ during two-phase testing was estimated using

$$
q_{\text {loss }}=\sum_{i=1}^{n} \frac{\left[\frac{\left(T_{i}-T_{S S}\right)}{R_{\text {down }, i}}\right]}{n}
$$

where $T_{i}$ is the temperature of $\mathrm{i}$-th diode on the TTC, $T_{s S}$ is the exterior temperature of the stainless steel fluid enclosure, $R_{\text {down }, i}$ is the downward thermal resistance of the $\mathrm{i}$-th diode, and $n$ is the number of diodes. This calculation method introduces a small error, as the diodes are not uniformly distributed across the area of the TTC.

The temperature drop due to conduction through the TTC $\left(\Delta T_{\text {cond }}\right)$ was estimated for each diode using

$$
\Delta T_{\text {cond }, i}=R_{\text {cond }, S i, i} \cdot\left(q-q_{\text {loss }}\right)
$$

where $q$ is the total TTC power. This calculation assumes one-dimensional conduction. The single- and two-phase heat transfer coefficients $(H T C)$ were calculated using

$$
H T C=\frac{q-q_{\text {loss }}}{A_{\text {chip }} \cdot\left(T_{i}-\Delta T_{\text {cond }, i}-T_{f}\right)}
$$

where $T_{f}$ is the local fluid temperature. For single-phase flow, the local temperature of the fluid was assumed to increase linearly from the microgap inlet to outlet. For two-phase flow, the local temperature of the fluid was calculated based on the estimated local saturation pressure. It was assumed that the fluid pressure decreased linearly from inlet to outlet. For the highest flow rate and highest heat flux, the maximum twophase pressure drop was $8.96 \mathrm{kPa}$, which corresponds to a drop in the local saturation temperature of $2.7 \mathrm{~K}$.

\section{Operating Sequence}

The following sequence was used while collecting the test data. The data acquisition rate was $25 \mathrm{~Hz}$.

1. Enable reservoir heater and allow temperature and pressure to stabilize

2. Enable recirculating chiller

3. Apply power to pump to circulate working fluid at desired flow rate

4. Apply power to preheater to achieve desired inlet fluid temperature

5. Adjust the pump control voltage, preheater power, and reservoir set point to achieve desired conditions at the evaporator inlet

6. Record data for 10 seconds when the flow loop has stabilized with the desired conditions at the evaporator inlet

7. Apply $1 \mathrm{~W} / \mathrm{cm}^{2}$ to the TTC, allow the TTC temperatures to stabilize, and record data for 10 seconds

8. Increase the power to the TTC in $1 \mathrm{~W} / \mathrm{cm}^{2}$ increments, recording data for 10 seconds at each increment, until vapor is generated on the TTC

9. After the onset of boiling, adjust the reservoir pressure, preheater power, and pump control voltage to maintain constant saturation pressure, degree of subcooling, and flow rate at the evaporator inlet

10. After the loop has stabilized, record data for 10 seconds and capture photos of the two-phase flow 
11. Increase the heat flux by $1 \mathrm{~W} / \mathrm{cm}^{2}$, adjust the reservoir temperature, preheater power, and pump control voltage to maintain constant saturation pressure, degree of subcooling, and flow rate at the evaporator inlet

12. Repeat step 10

13. Repeat steps 11 and 12 until the over temperature protection limit is hit, increasing the heat flux increment up to $4 \mathrm{~W} / \mathrm{cm}^{2}$ based on experience (however, the heat flux increment should be $1 \mathrm{~W} / \mathrm{cm}^{2}$ as the maximum heat flux is approached)

14. After the TTC temperature limit is reached, return the flow loop to the initial pump control voltage, preheater power, and reservoir set point, allow the flow loop to stabilize, and record data for 10 seconds

\section{Results and Analysis}

Single-phase and two-phase data points were collected at five orientations and three mass fluxes ranging from 349.1 to $853.5 \mathrm{~kg} / \mathrm{m}^{2}$-s. For each combination of mass flux and orientation, the heater power was increased until the overtemperature limit of $120^{\circ} \mathrm{C}$ was reached.

Figure 10 shows the critical heat flux (CHF) achieved at three mass flux increments with the evaporator in five orientations. $\mathrm{CHF}$ increased with increasing mass flux for all orientations, as expected. The horizontal heater up, vertical upflow, and sideways configurations produced CHF values that were 4.6 to $5.3 \%$ greater than those achieved in the horizontal heater down and vertical downflow configurations, which may be attributable to the differing role of gravity across orientations. In the horizontal heater up and vertical upflow configurations, gravity assists with vapor removal by accelerating it along or above the heated surface. In the horizontal heater down configuration, gravity pushes the vapor toward the heated surface and in the vertical downflow configuration, gravity pushes the vapor against the bulk fluid flow. It is also possible that the variation in the mass flux across orientations contributed to the variation in $\mathrm{CHF}$, with the lower mass flux values in the horizontal heater down and vertical downflow configurations contributing to the lower values of $\mathrm{CHF}$. Across the five orientations, the maximum to minimum variation in mass flux was $6.2 \%$ of the average at the lowest mass flux $\left(361.8 \mathrm{~kg} / \mathrm{m}^{2}-\mathrm{s}\right), 3.2 \%$ of the average at the intermediate mass flux $\left(593.3 \mathrm{~kg} / \mathrm{m}^{2}-\mathrm{s}\right)$, and $3.6 \%$ of the average at the highest mass flux $\left(817.9 \mathrm{~kg} / \mathrm{m}^{2}-\mathrm{s}\right)$.

Figure 11 shows the single- and two-phase heat transfer coefficients at the lowest mass flux (left column) and highest mass flux (right column) for three diodes located along the centerline of the microgap. The top row shows the heat transfer coefficients (HTCs) for the diode located near the microgap inlet, the middle row shows the HTCs for the diode located in the middle of the microgap, and the bottom row shows the HTCs for the diode located near the microgap outlet. The distance between the first and second and second and third diodes is $6.35 \mathrm{~mm}$ (for a total length of $12.70 \mathrm{~mm}$ ). As expected, the single-phase HTCs are much lower than the two-phase HTCs. At the onset of nucleate boiling, the heat transfer coefficient more than doubles for both mass fluxes. At the low mass flux, the vertical upflow orientation required the least superheat to initiate boiling and at the high mass flux, the horizontal down orientation required the least superheat to initiate boiling. The lack of clear trends in the required superheat to initiate boiling suggests that orientation is not the dominant mechanism affecting the onset of nucleate boiling in the present study.

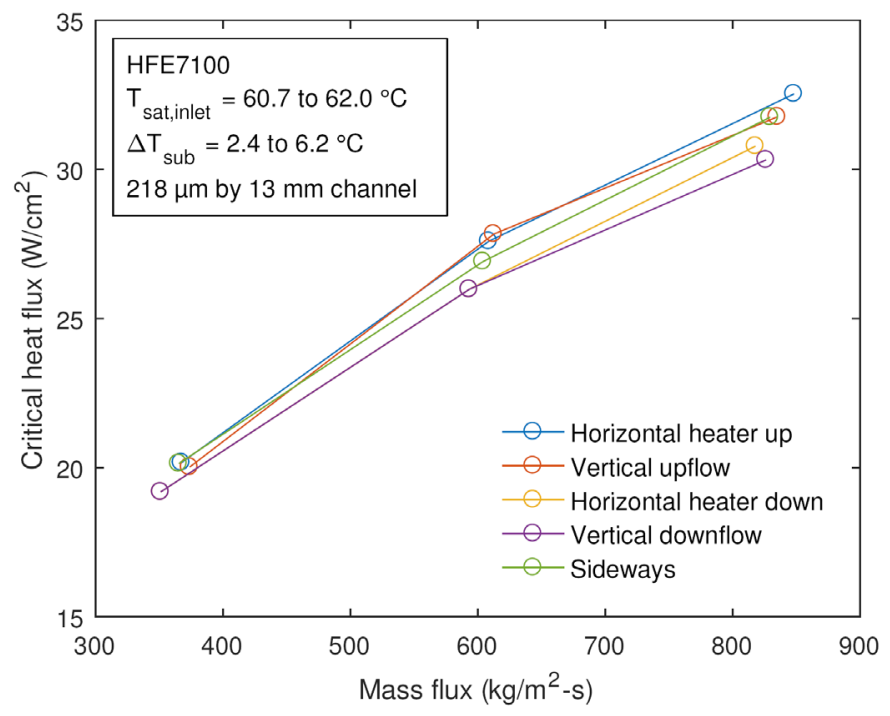

Figure 10: Flow boiling critical heat flux varies negligibly with orientation across three mass fluxes

Despite some variation in the onset of nucleate boiling, the heat transfer coefficients for each diode at each mass flux generally agree well across the five orientations studied, as evidenced by the excellent overlap of the five curves in each plot over much of the heat flux range. The biggest discrepancy appears to be for the diode near the channel inlet for the sideways configuration at the high mass flux, with slightly lower heat transfer coefficients than the other configurations. It is possible that this deviation resulted from a discrepancy in the inlet condition across orientations, as the heat transfer coefficients calculated based on the downstream diodes agree well with those for the other configurations and the $\mathrm{CHF}$ values for the sideways configuration were generally close to those for the preferable horizontal heater up and vertical upflow configurations.

Regarding the effect of axial position on heat transfer coefficient, both mass fluxes showed the highest heat transfer coefficients at the microgap inlet across much of the range of heat fluxes. In some cases, at low heat fluxes, vapor bubbles did not nucleate until some distance downstream of the microgap inlet; in those cases, the downstream heat transfer coefficients are higher than those at the microgap inlet until the heat flux increases to the point that vapor is generated closer to the microgap inlet. For all mass fluxes, the highest overall heat transfer coefficients are achieved near the microgap inlet just before CHF. At each mass flux, as CHF is approached, the heat transfer coefficient near the microgap outlet begins to depart from the straight line expected during nucleate boiling. No such change was seen in the upstream heat transfer coefficients. The deterioration could be indicative of the transition to the intermittent flow regime, which is characterized by lower heat transfer coefficients than those achieved during bubbly flow. 

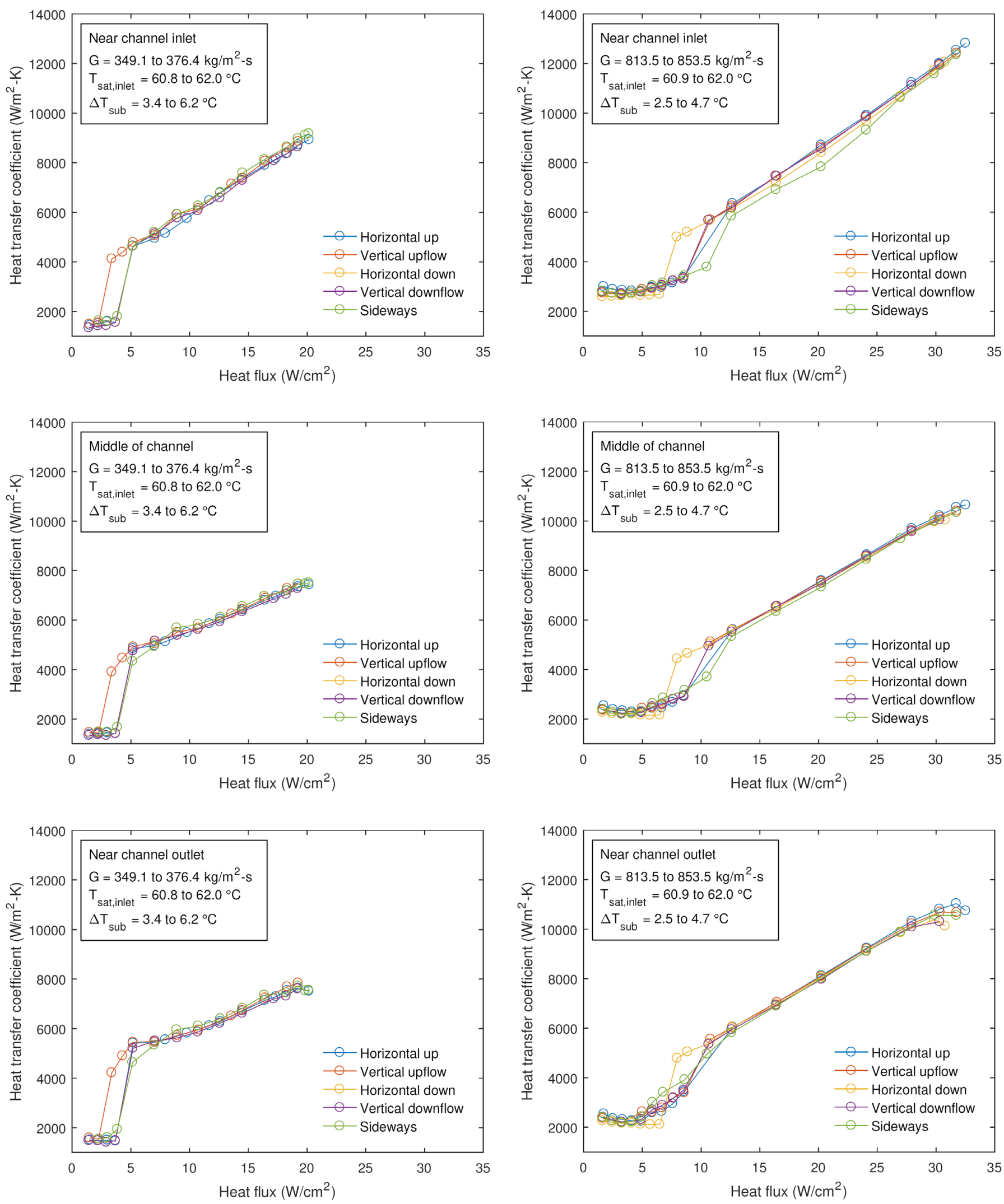

Figure 11: Single- and two-phase heat transfer coefficients for HFE7100 in a $218 \mu \mathrm{m}$ tall by $13.0 \mathrm{~mm}$ wide microgap as a function of evaporator orientation, mass flux, and sensor position 


\section{Conclusions and Future Work}

A study has been performed to assess the role of gravity on two-phase flows in miniature and microscale rectangular ducts. A comprehensive literature review revealed that many of the criteria proposed for the transition to microscale twophase flow, which is also the point at which the role of gravity is negligible, could be simplified to constant values of the Eötvös number. The wide variation among the proposed criteria may indicate that the transition cannot be captured by surface tension and gravity terms alone. Recent studies have incorporated the contact angle, mass flux, and fluid viscosity with some success.

The orientation-dependence of the two-phase thermofluid behavior of HFE7100 was studied at three mass fluxes in a microgap cooler with a height of $219 \mu \mathrm{m}$ and width of 13.0 $\mathrm{mm}$. The results revealed that gravity played a negligible role in the CHF and heat transfer coefficients achieved along the axial length of the microgap cooler. These results further call into question the use of the Eötvös number for assessing the transition to microscale behavior since - depending on the formulation used - the range of Eötvös number for the present system ranged from 0.25 to 233 across the five orientations studied. Additional work is required to assess the utility of the Eötvös number for predicting the microscale transition and/or to determine the appropriate length scales for calculating the Eötvös number.

Future work, using the existing test facility, will include microgap heights from 100 to $1000 \mu \mathrm{m}$ and mass fluxes from 100 to $2000 \mathrm{~kg} / \mathrm{m}^{2}$-s to better assess the effects of microgap height and fluid velocity on the orientation-dependence of the two-phase thermofluid behavior. Additional studies will be performed to assess other parameters, such as channel aspect ratio, heat flux, vapor quality, and/or flow regime. The role of flow regimes is of particular interest, as such a dependence could imply that each regime has a unique criterion and therefore knowledge of the flow regime would improve the predictive accuracy of the criteria. Bar-Cohen and Rahim previously found that a regime-informed approach improved the predictive accuracy of correlations for two-phase heat transfer coefficients [35]. It is also possible that gravity is important to only certain regimes and their transitions. For example, Taitel [36] found that in the case of the transitions to annular flow and dispersed bubble flow, the effect of gravity was negligible.

Ultimately, tests in a microgravity environment will be required to validate the ground-based test results. Microgravity validation would then allow the criteria that result from the research program to inform the design of gravity-insensitive flow boiling systems for future space missions.

$\begin{array}{cl}\text { Nomenclature } \\ A & \text { Area }\left(\mathrm{m}^{2}\right) \\ B o & \text { Bond number }(-) \\ C o & \text { Confinement number }(-) \\ D & \text { Tube diameter }(\mathrm{m}) \\ D_{h} & \text { Hydraulic diameter }(\mathrm{m}) \\ E o & \text { Eötvös number }(-) \\ F & \text { Force }(\mathrm{N}) \\ G & \text { Mass flux }\left(\mathrm{kg} / \mathrm{m}^{2}-\mathrm{s}\right) \\ H & \text { Channel height }(\mathrm{m})\end{array}$

$\begin{array}{cl}H D & \text { Horizontal heater down } \\ H U & \text { Horizontal heater up } \\ H T C & \text { Heat transfer coefficient }\left(\mathrm{W} / \mathrm{m}^{2}-\mathrm{K}\right) \\ L & \text { Channel length }(\mathrm{m}) \\ L a & \text { Laplace constant }(-) \\ P & \text { Channel wetted perimeter }(\mathrm{m}) \\ R & \text { Thermal resistance }(\mathrm{K} / \mathrm{W}) \\ R e & \text { Reynolds number }(-) \\ S W & \text { Sideways } \\ T & \text { Temperature }\left({ }^{\circ} \mathrm{C}\right) \\ V D & \text { Vertical downflow } \\ V U & \text { Vertical upflow } \\ W & \text { Channel width (m) } \\ g & \text { Acceleration due to gravity }\left(\mathrm{m} / \mathrm{s}^{2}\right) \\ k & \text { Thermal conductivity }(\mathrm{W} / \mathrm{m}-\mathrm{K}) \\ q & \text { Heat }(\mathrm{W}) \\ r & \text { Tube radius (m) } \\ t & \text { Thickness (m) }\end{array}$

Greek Letters

$\begin{array}{ll}\Omega & \begin{array}{l}\text { Ratio of gravitational forces to surface tension } \\ \text { forces }(-)\end{array} \\ \theta & \text { Contact angle }\left({ }^{\circ}\right) \\ \mu & \text { Dynamic viscosity }(\mathrm{kg} / \mathrm{m}-\mathrm{s}) \\ \rho & \text { Density }\left(\mathrm{kg} / \mathrm{m}^{3}\right) \\ \sigma & \text { Surface tension }(\mathrm{N} / \mathrm{m})\end{array}$

\section{Acknowledgements}

The authors gratefully acknowledge financial support from the NASA Headquarters Center Innovation Fund and significant technical contributions and test support from Keith Coulson and Mario Martins.

\section{References}

[1] Bar-Cohen, A., 2013, "Gen-3 thermal management technology: role of microchannels and nanostructures in an embedded cooling paradigm," J. Nanotech. Eng. Medicine, 4(2), pp. 1-3.

[2] National Aeronautics and Space Administration, 2015, "NASA Technology Roadmaps TA 14: Thermal Management Systems," http://www.nasa.gov/sites/default/files/atoms/files/2015_nasa _technology_roadmaps_ta_14_thermal_management_final.pd f.

[3] Sunada, E., Furst, B., Bhandari, P., Carroll, B., Birur, G. C., Hendricks, T., Kempenaar, J., Nagai, H., Daimaru, T., Sakamoto, K., Cappucci, S., and Mizerak, J., 2016, "A twophase mechanically pumped fluid loop for thermal control of deep space science missions," Int. Conf. Environmental Systems, Vienna, Austria. 
[4] Alam, T., Lee, P. S., and Jin L-W., 2013, Flow Boiling in Microgap Channels: Experiment, Visualization, and Analysis, Springer Science \& Business Media, New York.

[5] Kandlikar, S. G., 2010, "Scale effects on flow boiling heat transfer in microchannels: a fundamental perspective," Int. J. Thermal Sci., 49, pp. 1073-1085.

[6] Mehendale, S. S., Jacobi, A. M., and Shah, R. K., 2000, "Fluid flow and heat transfer at micro and meso-scales with application to heat exchanger design," Appl. Mech. Rev., 53(7), pp. 175-193.

[7] Kandlikar, S. G., 2002, "Fundamental issues related to flow boiling in minichannels and microchannels," Exp. Thermal Fluid Sci., 26, pp. 389-407.

[8] Suo, M., and Griffith, P., 1963, "Two-phase flow in capillary tubes," Technical Report No. 8581-24, Air Force Office of Scientific Research.

[9] Brauner, N., and Moalem Maron, D., 1992, "Identification of the range of 'small diameters' conduits, regarding twophase flow pattern transitions," Int. Comm. Heat Mass Transfer, 19, pp. 29-39.

[10] Brauner, N., 1990, "On the relations between two-phase flows under reduced gravity and Earth experiment," Int. Comm. Heat Mass Transfer, 17, pp. 271-282.

[11] Kew, P. A., and Cornwell, K., 1997, "Correlations for the prediction of boiling heat transfer in small-diameter channels," Applied Thermal Eng., 17(8-10), pp. 705-715.

[12] Cornwell, K., and Kew, P. A., 1993, "Boiling in small parallel channels," in Energy Efficiency in Process Technology, Elsevier Applied Science, London, Chap. 7.

[13] Triplett, K. A., Ghiaasiaan, S. M., Abdel-Khalik, S. I., and Sadowski, D. L., 1999, "Gas-liquid two-phase flow in microchannels Part I: two-phase flow patterns," Int. J. Multiphase Flow, 25, pp. 377-394.

[14] Triplett, K. A., Ghiaasiaan, S. M., Abdel-Khalik, S. I., LeMouel, A., and McCord, B. N., 1999, "Gas-liquid twophase flow in microchannels Part II: void fraction and pressure drop," Int. J. Multiphase Flow, 25, pp. 395-410.

[15] Li, J-M., and Wang, B-X., 2003, "Size effect on twophase regime for condensation in micro/mini tubes," Heat Transfer - Asian Research, 32(1), pp. 65-71.

[16] Cheng, P., and Wu, H. Y., 2006, "Mesoscale and microscale phase-change heat transfer," Advances Heat Transfer, 39, pp. 461-563.

[17] Ullmann, A., and Brauner, N., 2007, "The prediction of flow pattern maps in minichannels," Multiphase Sci. Tech., 19(1), pp. 49-73.

[18] Baldassari, C., and Marengo, M., 2013, "Flow boiling in microchannels in microgravity," Prog. Energy Combustion Sci., 39, pp. 1-36.

[19] Rausch, M. H., Kretschmer, L., Will, S., Leipertz, A., and Froba, A. P., 2015, "Density, surface tension, and kinematic viscosity of hydrofluoroethers HFE7000, HFE7100, HFE7200, HFE7300, and HFE7500," J. Chem. Eng. Data, 60, pp. 3759-3765.

[20] Ong, C. L., and Thome, J. R., 2011, "Macro-tomicrochannel transition in two-phase flow: Part 1 - Twophase flow patterns and film thickness measurements," Exp. Thermal Fluid Sci., 35, pp. 37-47.

[21] Harirchian, T., and Garimella, S. V., 2010, “A comprehensive flow regime map for microchannel flow boiling with quantitative transition criteria," Int. J. Heat Mass Transfer, 53, pp. 2694-2702.

[22] Harirchian, T., and Garimella, S. V., 2009, "The critical role of channel cross-sectional area in microchannel flow boiling heat transfer," Int. J. Multiphase Flow, 35, pp. 904913.

[23] Tibirica, C. B., and Ribatski, G., 2015, "Flow boiling phenomenological differences between micro- and macroscale channels," Heat Transfer Eng., 36, pp. 937-942.

[24] Lemmon, E. W., Huber, M. L., McLinden, M. O., 2013, NIST Standard Reference Database 23: Reference Fluid Thermodynamic and Transport Properties-REFPROP, Version 9.1, National Institute of Standards and Technology, Standard Reference Data Program, Gaithersburg, MD.

[25] Wagner, W., and Pruss, A., 2002, "The IAPWS formulation 1995 for the thermodynamic properties of ordinary water substance for general and scientific use," J. Phys. Chem. Ref. Data, 31(2), pp. 387-535.

[26] Lemmon, E. W., and Span, R., 2006, "Short fundamental equations of state for 20 industrial fluids," J. Chem. Eng. Data, 51, pp. 785-850.

[27] Tsoumpas, Y., Dehaeck, S., Rednikov, A., and Colinet, P., 2015, "Effect of Marangoni flows on the shape of thin sessile droplets evaporating into air," Langmuir, 31, pp. 13334-13340.

[28] Ohta, H., Baba, A., and Gabriel, K., 2002, "Review of existing research on microgravity boiling and two-phase flow," Ann. N.Y. Acad. Sci., 974, pp. 410-427.

[29] Celata, G. P., 2007, "Flow boiling heat transfer in microgravity: recent results," Microgravity Sci. Tech., 19, pp. 13-17.

[30] Konishi, C., and Mudawar, I., 2015, "Review of flow boiling and critical heat flux in microgravity," Int. J. Heat Mass Transfer, 80, pp. 469-493.

[31] Chen, T., and Garimella, S. V., 2006, "Effects of dissolved air on subcooled flow boiling of a dielectric coolant in a microchannel heat sink," J. Electronics Packaging, 128(4), pp. 398-404.

[32] Muller-Steinhagen, H., Epstein, N., and Watkinson, A. P., 1988, "Effect of dissolved gases on subcooled flow boiling heat transfer," Chem. Eng. \& Processing: Process Intensification, 23(2), pp. 115-124.

[33] Sawada, K., Kurimoto, T., Okamoto, A., Matsumoto, S., Asano, H., Kawanami, O., Suzuki, K., and Ohta, H., 2014, "Investigation of dissolved air effects on subcooled flow boiling heat transfer for boiling two-phase flow experiment aboard ISS," Int. Conf. Environmental Systems, Tucson, AZ. [34] An. B., Duan, Y., Tan, L., and Yang, Z., 2015, "Vapor pressure of HFE 7100," J. Chem. Eng. Data, 60, pp. 12061210.

[35] Bar-Cohen, A., and Rahim, E., 2009, "Modeling and prediction of two-phase microgap channel heat transfer characteristics," Heat Transfer Eng., 30(8), pp. 601-625.

[36] Taitel, Y., 1990, "Flow pattern transition in two phase flow," Int. Heat Transfer Conf., Jerusalem, Israel, pp. 237254. 